\title{
Spirulina Supplementation in Pregnant Women in the Dakar Region (Senegal)
}

\section{Khadim Niang1, Papa Ndiaye², Adama Faye1, Jean Augustin Diégane Tine¹, Fatou Bintou Diongue1, Maty Diagne Camara1, Mamadou Makhtar Leye', Anta Tal-Dia1}

\author{
${ }^{1}$ Health and Development Institute (ISED) of Cheikh Anta Diop University of Dakar (UCAD), Dakar, Senegal \\ ${ }^{2}$ Public Health Department of Gaston Berger University (UGB), Saint-Louis, Senegal \\ Email: khadimniang@outlook.com
}

How to cite this paper: Niang, K., Ndiaye, P., Faye, A., Tine, J.A.D., Diongue, F.B., Diagne Camara, M., Leye, M.M. and TalDia, A. (2017) Spirulina Supplementation in Pregnant Women in the Dakar Region (Senegal). Open Journal of Obstetrics and Gynecology, 7, 147-154.

http://dx.doi.org/10.4236/ojog.2017.71016

Received: January 2, 2017

Accepted: January 17, 2017

Published: January 20, 2017

Copyright $\odot 2017$ by authors and Scientific Research Publishing Inc. This work is licensed under the Creative Commons Attribution International License (CC BY 4.0).

http://creativecommons.org/licenses/by/4.0/

(c) (i) Open Access

\begin{abstract}
The fight against iron deficiency anemia in pregnant women is a public health priority, especially in sub-Saharan Africa. Spirulina is an alga very rich in iron, used as a dietary supplement. This research proposes to study its effect on the hemogloblobinaemia of pregnant women. This was a blind randomized cohort study with a supplemented group of spirulina $(1500 \mathrm{mg} / \mathrm{d})$ and a second supplemented with iron and folic acid supplementation (IFAS). Included in this study were pregnant women attending four health centers in the Dakar region, with pregnancy at $28^{\text {th }}$ amenorrhea, agreeing to participate and not having complications or twin pregnancies. Follow-up of the two groups was identical throughout the study from the $28^{\text {th }}$ week of amenorrhea to the $42^{\text {nd }}$ postnatal day. The study was conducted among 920 women, evenly distributed among the groups. IFAS allowed a statistically significant increase in hemoglobinemia with an average gain of $0.3 \mathrm{~g} / \mathrm{dl}$ between the $28^{\text {th }}$ and $32^{\text {nd }}$ weeks of amenorrhea $(p=0.022)$ and $0.2 \mathrm{~g} / \mathrm{dl}$ between the $28^{\text {th }}$ week and the delivery $(p=$ 0.043). Spirulina supplementation showed statistically higher gains than those observed with IFAS. These gains were $0.48 \mathrm{~g} / \mathrm{dl}$ between the $28^{\text {th }}$ and $32^{\text {nd }}$ weeks of amenorrhea and $0.36 \mathrm{~g} / \mathrm{dl}$ between the $28^{\text {th }}$ week and the delivery, with $p$ values less than 0.001 . Spirulina, more accessible to developing countries, is a good option to strengthen the arsenal of iron deficiency anemia control, and therefore maternal mortality.
\end{abstract}

\section{Keywords}

Maternal Mortality, Spirulina, Iron, Anemia, Supplementation, Senegal

\section{Introduction}

According to the World Health Organization, everyday 1500 women die from complications related to pregnancy or childbirth [1]. In 2005, there were an estimated 536,000 maternal deaths worldwide. 
Despite several advances in the accessibility and availability of maternal health services during this decade, maternal mortality remains high and it is estimated at 450 maternal deaths per 100,000 live births (LB) in sub-Saharan Africa [1] [2]. In Senegal, there are 392 deaths per 100,000 LB against 723 deaths per 100,000 LB in the region of Kolda where the health situation is unsatisfactory [3].

$80 \%$ of maternal deaths are related to severe hemorrhages, infections, hypertension disorders during pregnancy and dystocia. The $20 \%$ would be attributable to indirect factors including anemia [1]. Prevention of this anemia requires iron supplementation since the only source of iron, which is the diet, sometimes does not sufficiently meet the needs of the pregnant woman [4] [5] [6].

Spirulina is a natural alga, rich in protein and containing a high concentration of nutrients. The term "spirulina" is considered to be a vernacular name attributed to Arthrospira and Spirulina, two cyanobacteria known as "blue-green algae". It is known for its virtues in the fight against malnutrition, anemia and the strengthening of immune defenses [7]. It is in this direction that this research studies the contribution of a supplement in spirulina in the pregnant women of the region of Dakar.

\section{Framework, Tools and Methods}

\subsection{Framework}

This study was carried out in the region of Dakar, capital of Senegal located in the Peninsula of Cape Verde. The population of the Dakar Region was estimated at 2,647,748 inhabitants in 2011. Although it covers only $0.28 \%$ of the national territory, Dakar has the highest population density of the country with 4554 inhabitants per $\mathrm{km}^{2}$. The rate of natural increase is $2.5 \%$ and young people represent more than two thirds of the population of the Dakar Region. Almost all of the population is urban (97\%).

The medical region of Dakar has ten health districts, which are the operational entities of the health system. This study was carried out at the health districts of Guediawaye, Mbao, Pikine and Dakar Nord, selected at random. The use of NPCs was $71.5 \%$ in 2013 , or $18.5 \%$ below the national target of $90 \%$. Of the 108,285 pregnancies expected in $2012,68,454$ deliveries were recorded in the facilities, of which 58,328 were attended by skilled personnel.

\subsection{Type of Study}

This was an exposed-unexposed comparative cohort study on pregnant women from the 3rd trimester of pregnancy, prenatal consultation (PNC) in the 4 health centers of the selected districts.

Were included, all women with a pregnancy of 28 weeks of completed amenorrhea (WCA). The refusal to participate, the presence of complication requiring special management of pregnancy and twinning were the criteria for non-inclusion. Women who were lost sight of or had dropped out of the study were excluded from the study.

By taking a prevalence of anemia among women in the Dakar region of $31 \%$ (corresponding to the prevalence expected in the non-exposed group), an exposure ratio of 1 , a power of $90 \%$ and an expected relative risk of 0.75 , the desired size of the sample was 866 women [8]. A 5\% height adjustment was made to compensate for the loss of 
sight, which resulted in a rounded size of 920 women to be surveyed.

Thus, 115 women exposed and 115 not exposed to spirulina had to be selected and monitored at each of the four health centers. All cases excluded from the study were replaced until the desired strength was achieved.

The designation of the search tool was made after the woman's consent had been obtained, based on a randomization list previously established at the start of the study.

\subsection{Ethical Considerations}

Participation in this study was voluntary after obtaining the informed consent of the woman. Anonymity was respected and the data collected were secured in order to preserve their confidentiality. All care costs for this study (consultations, biology, childbirth, supplements) were free for all women enrolled. An insurance system to deal with possible incidents and complications related to the taking of spirulina has also been taken into account. The approval of the National Ethics Committee for Health Research in Senegal was obtained before the start of the field activities, as well as the necessary administrative authorizations.

\subsection{Women's Monitoring}

Women were recruited after informed consent at 28 weeks of amenorrhea. Follow-up, carried out by midwives, consisted in visits including an interrogation, a clinical examination and biological tests (hemoglobin levels, glycosuria and proteinuria). Women were evaluated at baseline ( $28^{\text {th }}$ week of amenorrhea), followed by 32 weeks of amenorrhea, at delivery and 42 days after delivery.

Women in the Exposed group received a daily dose of $1.5 \mathrm{~g}$ (3 tablets of $500 \mathrm{mg}$ ) of spirulina. Women in the Non-exposed group received conventional iron (ferrous sulfate) $90 \mathrm{mg}$ and folic acid supplementation $1 \mathrm{mg} /$ day. In both groups, catches were made of inclusion on the $42^{\text {nd }}$ day after childbirth.

The Spirulina tablets were green, and those of iron were pink or red. Spirulina used in this survey was provided free of charge by the health education association after acquisition of administrative authorizations for use in the research, but also in the context of the supplementation of children and adults as a food supplement.

\subsection{Data Collection Tool}

A previously tested and corrected questionnaire was administered to the women included in the study. This questionnaire included several aspects such as personal characteristics, women's gynecological and obstetric history, anthropometric measurements (weight, height), clinical and biological data (temperature, hemoglobinemia, glycosuria, albuminuria) and any problems encountered.

The records were filled out during consultations and childbirth by the midwives responsible for following pregnant women at the health centers concerned.

\subsection{Data Capture and Analysis}

The data thus collected had been entered in duplicate on Epi info version 3.5.3 and analyzed with software $\mathrm{R}$ according to a per protocol procedure. 
The primary endpoint was the evolution of hemoglobinemia in women. Secondary endpoints were the clinical and biological tolerance of spirulina, pregnancy outcome, hemoglobinemia, and neonatal weight. A univariate analysis made it possible to describe the variables and to have their proportions for the qualitative variables or their averages and standard deviations for the quantitative variables.

A comparison of the characteristics of the two groups was made at the inclusion to determine the level of comparability of the two groups, and then on the subsequent contacts. The $\mathrm{Chi}^{2}$ and Fisher tests were used for proportional comparisons and the Student test for mean comparisons (in paired or not paired) by setting the risk of alpha error at $5 \%$.

Data analysis in the post-natal period only concerned women who gave birth to a newborn child.

\section{Results}

The study was conducted on a total of 1201 women recruited over a period of 16 months. Of these, 920 received full follow-up until the $42^{\text {nd }}$ post-natal day, or $76.6 \%$. A difference in protocol was observed in 281 women because they were lost to follow-up (227\% or $80.8 \%$ ), missed appointments (44\% or $15.7 \%$ ) or abandoned for family reasons $(10 \%$ or $3.6 \%)$. There was no statistically significant difference in the reasons for exclusion between the two groups studied ( $p=0.48$ ).

Statistical analysis showed that the two groups studied had superimposable characteristics at the time of inclusion (Table 1).

The mean hemoglobin levels of women in the two groups were statistically superimposable at the time of inclusion in the study with a rate of $10.7 \mathrm{~g} / \mathrm{dl}$ for women in the Exposed group versus 10.5 for the second group and a $p$-value of 0.21 . Hemoglobinaemia showed an upward trend in each group throughout the study and in a statistically significant manner (Table 2).

The comparison of the evolution of hemoglobinaemia between the two groups showed a statistically significant difference. Indeed, the increase in hemoglobinaemia in

Table 1. Comparison of characteristics of women in both groups at study entry $(N=920)$.

\begin{tabular}{|c|c|c|c|c|}
\hline Variables & Settings & $\begin{array}{c}\text { Exposed } \\
\text { Spiriluna Group }\end{array}$ & $\begin{array}{l}\text { "Non-Exposed" } \\
\text { Spirulina Group }\end{array}$ & $p$-value \\
\hline \multirow{2}{*}{ Age } & Average & 26.6 & 26.9 & \multirow{2}{*}{0.46} \\
\hline & Standard deviation & 6.22 & 6.13 & \\
\hline \multirow{2}{*}{$\begin{array}{l}\text { Number of } \\
\text { pregnancies }\end{array}$} & Average & 1.75 & 2.01 & \multirow{2}{*}{0.05} \\
\hline & Standard deviation & 1.87 & 2.02 & \\
\hline \multirow{2}{*}{ Weight (in Kg) } & Average & 66.3 & 66.3 & \multirow{2}{*}{0.99} \\
\hline & Standard deviation & 13.1 & 13.2 & \\
\hline \multirow{2}{*}{ Size (in $\mathrm{cm}$ ) } & Average & 1.65 & 1.65 & \multirow{2}{*}{0.32} \\
\hline & Standard deviation & 6.3 & 6.5 & \\
\hline \multirow{2}{*}{$\mathrm{Hb}(\mathrm{en} \mathrm{g} / \mathrm{dl})$} & Average & 10.7 & 10.5 & \multirow{2}{*}{0.21} \\
\hline & Standard deviation & 1.36 & 1.26 & \\
\hline
\end{tabular}


Table 2. Evolution of hemoglobinemia during the various follow-up phases $(\mathrm{N}=920)$.

\begin{tabular}{cccc}
\hline Study groups & Follow-up phases & Average increase & $p_{\text {-value }}^{*}$ \\
\hline Spirulina Non & Between $28^{\text {th }}$ WCA and $32^{\text {nd }}$ WCA & +0.30 & $<0.001$ \\
Exposed Group & Between $28^{\text {th }}$ WCA and childbirth & +0.20 & $<0.001$ \\
& Between birth and $42^{\text {nd }}$ day post natal & +0.92 & $<0.001$ \\
& & & $<0.001$ \\
Spirulina & Between $28^{\text {th }}$ WCA and $32^{\text {nd }}$ WCA & +0.48 & $<0.001$ \\
Exposed Group & Between $28^{\text {th }}$ WCA and childbirth & +0.36 & $<0.001$ \\
\hline
\end{tabular}

${ }^{*} t$ test paired with a difference of 0 .

the group exposed to spirulina was statistically higher than that of the exposed group from the first month of exposure with respective gains of $0.48 \mathrm{~g} / \mathrm{dl}$ and $0.30 \mathrm{~g} / \mathrm{dl}$ and a $p$-value of 0.022 . The same observation is made when comparing the evolution of hemoglobinemias between the two groups between inclusion and delivery. The more consistent increase in hemoglobinemia in the group exposed to spirulina also remained after childbirth (Table 3 ).

The evolution of pregnancy between the two groups was statistically superimposable (Table 4). Indeed, the mode of delivery, the occurrence of a hemorrhage of the delivery, the viability of the newborn and the presence of a malformation in the latter. In women no case of albuminuria was objectivized from inclusion to the $42^{\text {nd }}$ postnatal day. Only one case of glycosuria was found in the group exposed to spirulina (Table 4).

The average weight of newborns at birth was $3018 \mathrm{~g}$ for women in the group exposed to spirulina and $2999 \mathrm{~g}$ for the group under iron and folic acid supplementation (IFAS). This difference was not statistically significant $(p=0.54)$. On the $42^{\text {nd }}$ postnatal day this weight was $4445 \mathrm{~g}$ for the group under spirulina and $4323 \mathrm{~g}$ for the group under IFAS. The mean weight gain between birth and the $42^{\text {th }}$ postnatal day was $1432 \mathrm{~g}$ in infants under spirulina group and $1318 \mathrm{~g}$ for those under IFAS group with a statistically significant difference $(p=0.01)$.

The average hemoglobinaemia of infants at day 42 postnatal was $13.8 \mathrm{~g} / \mathrm{dl}$ for those in the group exposed to spirulina, and $12.6 \mathrm{~g} / \mathrm{dl}$ for those in the group whose mother was under IFAS. This difference was statistically significant $(p<0.001)$.

\section{Discussions}

This study sought to determine the contribution of spirulina supplementation to hemoglobinemia in pregnant women. The main limitations of this study are the absence of groups receiving neither spirulina nor iron. This was not possible because of the ethical constraints that this design could have posed to the over-exposure to the risk of anemia that this could entail. The same constraint also led us to start the spirulina supplementation at the $28^{\text {th }}$ week, so that the women included had already received iron and folic acid supplementation before being enrolled in this study. The other limit is represented by the absence of a follow-up of the catches of the products at home. Indeed, adherence to treatment was only indirectly determined on the basis of the women's statement, which exposes them to a prevarication bias. However, the study was able to reach the desired number of subjects, and the latter could be followed under the 
Table 3. Comparison of the evolution of hemoglobinaemia between the two groups during the various follow-up phases $(\mathrm{N}=920)$.

\begin{tabular}{cccc}
\hline Follow-up phases & $\begin{array}{c}\text { Evolution in } \\
\text { spirulina exposed }\end{array}$ & $\begin{array}{c}\text { Evolution in } \\
\text { non-exposed spirulina }\end{array}$ & $p$-value \\
\hline Between 28 $8^{\text {th }}$ WCA and 32 $2^{\text {nd }}$ WCA & +0.48 & +0.30 & 0.022 \\
Between 28 $8^{\text {th }}$ WCA and childbirth & +0.36 & +0.20 & 0.043 \\
Between birth and 42 ${ }^{\text {nd }}$ day post natal & +1.37 & +0.92 & $<0.001$ \\
\hline
\end{tabular}

Table 4. Comparison of the characteristics of the evolution of pregnancy between the two groups $(\mathrm{N}=920)$.

\begin{tabular}{|c|c|c|c|c|}
\hline Variables & $\begin{array}{l}\text { Terms and } \\
\text { Conditions }\end{array}$ & $\begin{array}{c}\text { Spirulina } \\
\text { Exposed Group }\end{array}$ & $\begin{array}{l}\text { Spirulina Non } \\
\text { Exposed Group }\end{array}$ & $p$-value \\
\hline Childbirth mode & $\begin{array}{c}\text { Childbirth } \\
\text { Caesarean delivery }\end{array}$ & $\begin{array}{c}440 \\
20\end{array}$ & $\begin{array}{c}438 \\
22\end{array}$ & 0.75 \\
\hline $\begin{array}{c}\text { Haemorrhage } \\
\text { of the deliverance }\end{array}$ & $\begin{array}{l}\text { Yes } \\
\text { No }\end{array}$ & $\begin{array}{c}8(1.7 \%) \\
452(98.3 \%)\end{array}$ & $\begin{array}{c}8(1.7 \%) \\
452(98.3 \%)\end{array}$ & 1 \\
\hline Stillborn & $\begin{array}{l}\text { Yes } \\
\text { No }\end{array}$ & $\begin{array}{c}6(1.3 \%) \\
454(98.7 \%)\end{array}$ & $\begin{array}{c}3(0.7 \%) \\
457(99.3 \%)\end{array}$ & 0.51 \\
\hline $\begin{array}{l}\text { Malformation } \\
\text { in the Newborn }\end{array}$ & $\begin{array}{l}\text { Yes } \\
\text { No }\end{array}$ & $\begin{array}{c}1(0.2 \%) \\
459(99.8 \%)\end{array}$ & $\begin{array}{c}2(0.4 \%) \\
458(99.6 \%)\end{array}$ & 1 \\
\hline Albuminuria & $\begin{array}{l}\text { Yes } \\
\text { No }\end{array}$ & $\begin{array}{c}0(0 \%) \\
460(100 \%)\end{array}$ & $\begin{array}{c}0(0 \%) \\
460(100 \%)\end{array}$ & 1 \\
\hline Glycosuria & $\begin{array}{l}\text { Yes } \\
\text { No }\end{array}$ & $\begin{array}{c}1(0.2 \%) \\
459(99.8 \%)\end{array}$ & $\begin{array}{c}0(0.0 \%) \\
460(100 \%)\end{array}$ & 1 \\
\hline
\end{tabular}

same conditions until the $42^{\text {nd }}$ postnatal day. Randomization also allowed two groups of pregnant women with superimposable statistical characteristics to study the supply of spirulina supplementation versus iron and folic acid supplementation with good reliability.

The efficiency of iron supplementation in improving hemoglobinemia in pregnant women has been strongly shared in the literature [9] [10] [11]. Indeed, the World Health Organization [9] recommends iron supplementation through iron-rich medicines and foods for women in countries with limited to moderate resources. Peña-Rosas [10] pointed out in a randomized, systematic review that iron supplementation in pregnant women during pregnancy would result in a hemoglobin gain of $8.8 \mathrm{~g} / \mathrm{l} \mathrm{com-}$ pared to non-supplemented women. The results of our study made it possible to objectify this contribution of iron and folic acid supplementation on the hemoglobinemia of the pregnant woman. This hemoglobinemia showed an increase of $0.3 \mathrm{~g} / \mathrm{dl}$ between the $28^{\text {th }}$ and $32^{\text {nd }}$ week of amenorrhoea and $0.2 \mathrm{~g} / \mathrm{dl}$ between the $32^{\text {nd }}$ week of amenorrhoea and childbirth. A more significant increase was observed between childbirth and the $42^{\text {nd }}$ postnatal day. This increase could be attributed to the disappearance of the phenomenon of haemodilution observed during pregnancy [12].

This study demonstrated improvement in hemoglobinemia through spirulina supplementation. Indeed, the hemoglobinemia of women in the group exposed to spirulina 
showed a statistically significant increase in inclusion at the $32^{\text {nd }}$ week of amenorrhoea, but also of this $32^{\text {nd }}$ week at delivery and of delivery in the $42^{\text {nd }}$ Day post-natal.

This increase could be explained by the richness of spirulina in iron. It could also be explained by the effects of phycocyanin contained in spirulina. Phycocyanin is a respiratory pigment of a polypeptide nature specific to spirulina. This complex molecule acts on the bone marrow by stimulating the evolution and differentiation of stem cells from red and white bloodlines. This action was demonstrated by the work of Zhang C. [13], who compared the action of phycocyanin to that of the hormonal systems (kidneys and bone marrow) regulating erythropoiesis. This action of phycocyanin could explain the greater increase in hemoglobinemia observed in women on spirulina compared to women under iron supplementation.

In addition to having good efficacy in improving hemoglobinemia in pregnant women, spirulina was well tolerated. Indeed no case of albuminuria was objectified from inclusion to the $42^{\text {nd }}$ day of follow-up. Only one case of glycosuria was diagnosed in the group of women on spirulina. This shows the good biological tolerance of spirulina. With regard to the outcome of pregnancy, the proportion of stillbirths, caesarean sections, delivery haemorrhages and malformation in newborns was statistically superimposed between the two groups studied.

In the newborn and infant, spirulina has been shown to be effective in improving weight and hemoglobinemia. Indeed, measuring the weight of newborn babies at birth had not made it possible to objectify a statistically significant difference between the two groups. However, weight gain between birth and 42 days post-natal was higher in the group of women exposed to spirulina $(p=0.01)$. This is in accordance with data from the literature in older children [14] [15].

To this weight gain was added hemoglobinemia of infants at the $42^{\text {nd }}$ postnatal day higher in the group exposed to spirulina. The mean hemoglobin level of infants was $13.7 \mathrm{~g} / \mathrm{dl}$ in the spirulina group versus $12.6 \mathrm{~g} / \mathrm{dl}$ in the IFAS group with a statistically significant difference $(p<0.001)$.

\section{Conclusion}

Spirulina supplementation in pregnant women in the last trimester is more effective than iron and folic acid supplementation in improving hemoglobinemia and hence preventing and treating anemia. This higher efficacy is accompanied by a good tolerance of spirulina and a significant gain in the weight and hemoglobinemia of infants if supplementation is continued until the $42^{\text {nd }}$ postnatal day. Being a natural product accessible to the vast majority of the population and having already proved its action against hunger, it is an element that could strengthen the arsenal of maternal and newborn health interventions in developing countries.

\section{Acknowledgements}

Acknowledgments to the Health Education Association who funded this study, to all the women who agreed to participate and the staff of the health centers that allowed this survey. 


\section{Conflict}

No conflict of interest to declare.

\section{References}

[1] WHO (2007) Maternal Mortality in 2005. WHO, Geneva, 16-18.

[2] United Nations Organization (2015) Millenium Development Goals-Report 2014. United Nations.

[3] National Agency of Statistics and Demography-Regional Service of Statistics and Demography of Kolda (2011) Economic and Social Regional Situation 2010. Ministry of Economy and Finance of Senegal, 65-78.

[4] Leslie, J. (1991) Women's Nutrition: Is This the Key to Improving Family Nutrition in Developing Countries? Health Policy and Planning, 6.

[5] Lemonnitv, D. and Ingenblwk, C.I.Y. (1989) Nutritional Deficiencies in Developing Countries. Third Day of the GIRM. KARTHALA.ACCT, Paris, 280-284.

[6] Ayoubi, J.M., Hirt, R., Badiou, W., Hininger-Favier, I., Zraik-Ayoubi, F., Berrebi, A. and Pons, J.C. (2012) Nutrition and Pregnant Woman. EMC of Obstetric Gynecology, 5-7.

[7] Bories, G. and Tulliez, J. (1975) Determination of 3, 4-Benzopyrene in Spiruline Algae Produced and Treated by Various Procedures. Annales de la Nutrition et de P Alimentation, 29, 573-575.

[8] Humphry, R.W., Cameron, A. and Gunn, G.J. (2004) A Practical Approach to Calculate Sample Size for Herd Prevalence Surveys. Preventive Veterinary Medicine, 65, 173-188. https://doi.org/10.1016/j.prevetmed.2004.07.003

[9] WHO (2012) Guideline: Daily Iron and Folic Acid Supplementation in Pregnant Women.

[10] Peña-Rosas, J.P. and Viteri, F.E. (2012) Effects and Safety of Preventive Oral Iron or Iron + Folic Acid Supplementation for Women during Pregnancy. Cochrane Database of Systematic Reviews, 2009, CD004736.

[11] Lumbiganon, P. (2007) Multiple Micronutrient Supplementation in Pregnant Women RHL Commentary. WHO Reproductive Health Library, WHO, Geneva.

[12] Lejeune, V. (2009) Conduct to Be Taken during Pregnancy. Realities in GynecologyObstetrics, March/April, No. 136.

[13] Zhang, C. (1994) The effects of polysaccharide et phycocyanin from Spirulina platensis variety on peripheral blood and hematopoietic system of bone marrow in mice. Second AsiaPacific Conference on Alga Biotechnology, 25-27 April 1994.

[14] Sachdeva, R., Kaur, R. and Kaur, S.J. (2004) Effect of Supplementation of Spirulina on the Haematological Profile and Intellectual Status of School Girls (7 - 9 Years). Journal of Human Ecology, 15, 105-108.

[15] Gueye, B.C. (2004-2005) The Improvement of the Nutritional Status by Spirulina of Pupils Being Initiated by the Commune of Dakar: A Contribution to the Achievement of Better School Performance. [Memory DEA of Medicine]. Institute of Health and Development Faculty of Medicine, Dakar. 
Submit or recommend next manuscript to SCIRP and we will provide best service for you:

Accepting pre-submission inquiries through Email, Facebook, LinkedIn, Twitter, etc. A wide selection of journals (inclusive of 9 subjects, more than 200 journals)

Providing 24-hour high-quality service

User-friendly online submission system

Fair and swift peer-review system

Efficient typesetting and proofreading procedure

Display of the result of downloads and visits, as well as the number of cited articles Maximum dissemination of your research work

Submit your manuscript at: http://papersubmission.scirp.org/

Or contact ojog@scirp.org 